\title{
Meta-analysis of clodronate and breast cancer survival
}

\author{
TC $\mathrm{Ha}^{*}, \mathbf{1}$ and $\mathbf{H ~ L i}^{1}$ \\ 'Division of Clinical Trials and Epidemiological Sciences, National Cancer Centre, II Hospital Drive, Singapore 1696 I0, Singapore
}

\begin{abstract}
Clinical trials have reported conflicting results on whether oral clodronate therapy improves survival in breast cancer patients. This study was undertaken to evaluate further the effect of oral clodronate therapy on overall survival, bone metastasis-free survival and nonskeletal metastasis-free survival among breast cancer patients. An extensive literature search was undertaken for the period 1966 to July 2006 to identify clinical trials examining survival in breast cancer patients who received 2 or 3 years of oral clodronate therapy at $1600 \mathrm{mg} \mathrm{day}^{-1}$ compared with those without therapy. Meta-analyses were carried out separately for patients diagnosed with advanced breast cancer and early breast cancer. Our meta-analysis found no evidence of any statistically significant difference in overall survival, bone metastasis-free survival or nonskeletal metastasis-free survival in advanced breast cancer patients receiving clodronate therapy or early breast cancer patients receiving adjuvant clodronate treatment compared with those who did not receive any active treatment.

British Journal of Cancer (2007) 96, I796- I80I. doi:10.1038/sj.bjc.660366 I www.bjcancer.com

Published online 27 February 2007

(C) 2007 Cancer Research UK
\end{abstract}

Keywords: breast cancer; survival; clodronate; trial; meta-analysis

Bone is the most common site of distant recurrence in breast cancer and affects an estimated $70 \%$ of women with advanced breast cancer (Lipton, 2003). Bone metastases results in not only skeletal-related events such as pathological fractures and spinal cord compression, but also a reduction in survival (Coleman, 1997). Treatment for breast cancer that has metastasised to the bone can improve quality of life, but the cancer is incurable. Therefore, it is important to investigate ways of preventing or delaying bone metastasis. Randomised clinical trials, comparing bisphosphonates, such as clodronate, with either placebo or no treatment, have shown a reduction in skeletal complications and skeletal-related events from bone metastases (Kristensen et al, 1999; Powles et al, 2006).

In patients with early breast cancer, clodronate is currently the only bisphosphonate shown to improve survival and to reduce the incidence of bone metastases in randomised controlled trials (Diel et al, 1998; Dando and Wiseman, 2004; Powles et al, 2006). However, clinical trials have not shown a clear positive impact on breast cancer survival with a range of conflicting opinion remaining (Elomaa et al, 1988; Kanis et al, 1996; Diel et al, 1998; Kristensen et al, 1999; Mardiak et al, 2000; Saarto et al, 2001; Powles et al, 2006). In terms of overall survival, two trials found a statistically significant longer overall survival for breast cancer patients who received adjuvant clodronate (Diel et al, 1998; Powles et al, 2006) whereas one trial found a statistically significant shorter overall survival (Saarto et al, 2001). Two trials found a statistically significant longer bone metastasis-free survival for those who received adjuvant clodronate (Diel et al, 1998; Powles et al, 2006) whereas one trial found no difference (Saarto et al, 2001). In advanced breast cancer patients, one trial suggests a

*Correspondence: Dr TC Ha; E-mail: ha.tam.cam@nccs.com.sg Received 7 November 2006; revised 3 January 2007; accepted 29 January 2007; published online 27 February 2007 delayed time to bone metastasis formation (Kanis et al, 1996) whereas another trial did not (Mardiak et al, 2000). In terms of nonskeletal metastasis-free survival, the results were ambivalent with two trials finding a statistically significant longer nonskeletal metastasis-free survival for those receiving adjuvant clodronate (Diel et al, 1998; Saarto et al, 2001) whereas one did not (Powles et al, 2006). These conflicting results demand the conduct of a meta-analysis to determine the effect of oral clodronate therapy on breast cancer survival.

The purpose of this study is to examine the effect of oral clodronate $1600 \mathrm{mg} \mathrm{day}^{-1}$ given for 2 or 3 years for breast cancer patients in terms of overall survival, bone metastasis-free survival and nonskeletal metastasis-free survival, in addition to their standard surgery, radiotherapy, chemotherapy or hormone therapy by means of meta-analysis using aggregate patient data.

\section{MATERIALS AND METHODS}

\section{Types of trials}

Trials included randomised clinical trials that investigated overall, bone metastasis-free or nonskeletal metastasis-free survival among breast cancer patients receiving oral clodronate therapy or no active treatment (Table 1).

\section{Types of participants}

Participants were patients with histologic- or cytologic-proven breast cancer but no prior history of other malignant diseases (besides recurrent breast cancer) or bisphosphonate usage. In this study, advanced breast cancer was defined as patients who had either recurrent breast cancer or metastatic breast cancer (not primary breast cancer) at the time of enrolment in the study (Elomaa et al, 1988; Kanis et al, 1996; Kristensen et al, 1999; 
Table I Summary of the included phase III trials investigating clodronate and breast cancer survival

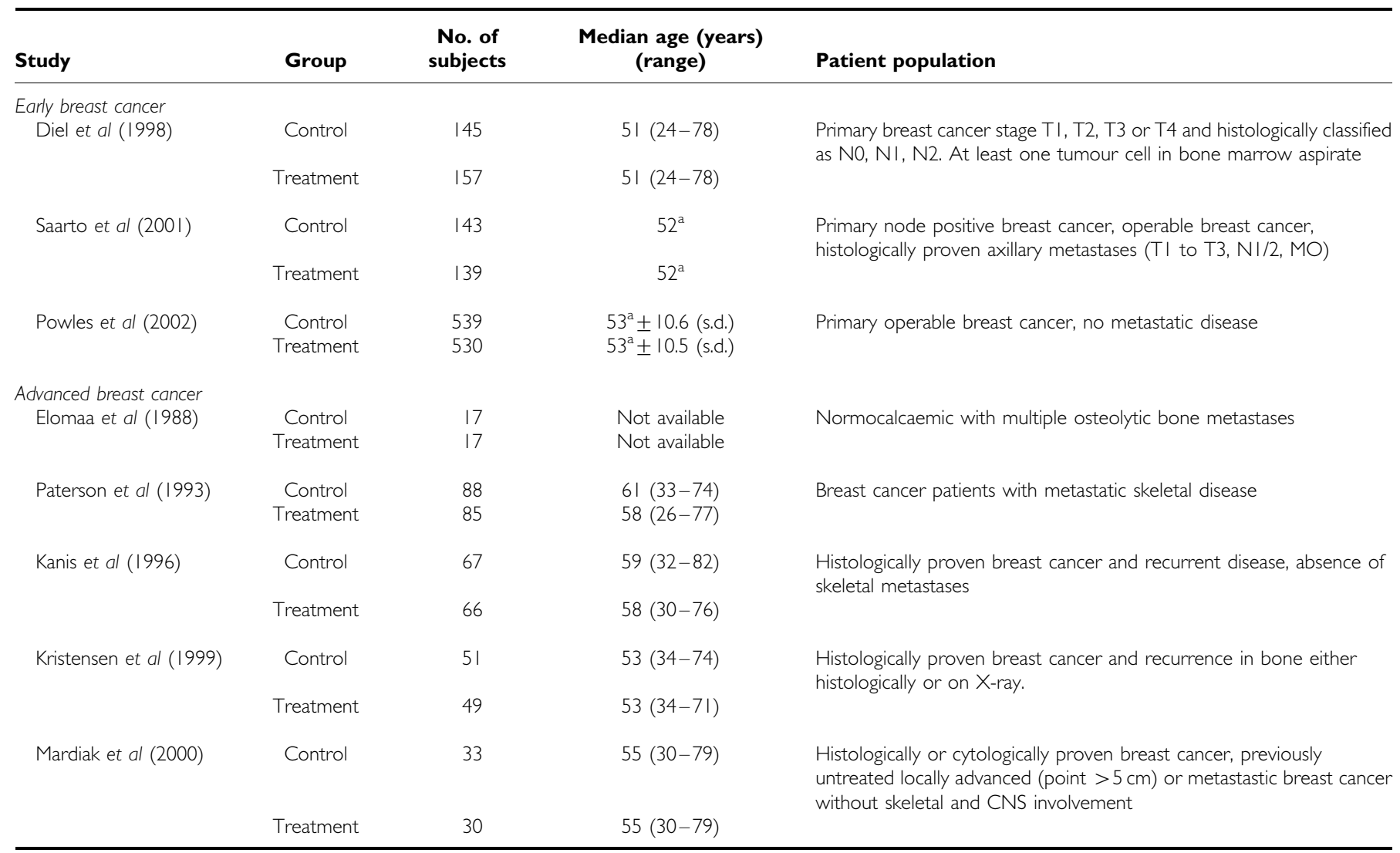

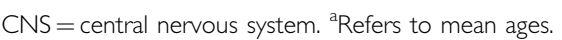

Table 2 List of individual studies with overall survival, bone metastasis-free survival and nonskeletal metastasis-free survival

\section{HR $(95 \% \mathrm{Cl})$}

\begin{tabular}{|c|c|c|c|}
\hline Study & Overall survival & Bone metastasis-free survival & Nonskeletal metastasis-free survival \\
\hline \multicolumn{4}{|l|}{ Early breast cancer } \\
\hline Diel et al (1998) & $0.26(0.13,0.55)$ & $0.36(0.18,0.71)$ & $0.38(0.20,0.72)$ \\
\hline Powles et al (2002) & $0.77(0.59,1.00)$ & $0.69(0.48,0.99)$ & $0.84(0.62,1.13)$ \\
\hline \multicolumn{4}{|l|}{ Advanced breast cancer } \\
\hline Elomaa et al (1988) & $0.27(0.11,0.66)$ & Not available & Not available \\
\hline Kanis et al (1996) & $0.92(0.59,1.42)$ & $0.52(0.27,1.02)$ & Not available \\
\hline
\end{tabular}

$\mathrm{Cl}=$ confidence interval; $\mathrm{HR}=$ hazard ratio.

Mardiak et al, 2000). Early breast cancer was defined as patients who were diagnosed with primary operable breast cancer (Diel et al, 1998; Saarto et al, 2001; Powles et al, 2006).

\section{Types of interventions}

The types of interventions were oral clodronate $1600 \mathrm{mg} \mathrm{day}^{-1}$ given for either 2 or 3 years, compared with an identical placebo or no treatment.

\section{Types of outcome measures}

Outcome measures included for 5-year overall, bone metastasisfree and nonskeletal metastasis-free survival (Table 2).

\section{Search strategy for identifying trials}

A comprehensive search was conducted for relevant published primary trials using the following online electronic bibliographic databases until the 7th of July 2006 with no language restriction: PubMed from 1950 to 2006, Journals@Ovid Full text from 1993 to 2006, SCOPUS from 1966 to 2006, COCHRANE database of systematic reviews until the second quarter of 2006 and Cochrane Central Register of Controlled Trials until the second quarter of 2006, LILACS from 1982 to 2006 . The search terms employed were clodronate, breast cancer, survival, mortality and trial. A manual search was conducted of the following journals: Breast Cancer Research and Treatment (1981 t0 July 2006), Clinical Oncology (1989 to July 2006), Breast Cancer Research (1999 to June 2006), 
British Journal of Cancer (1999 to July 2006) and Journal of Clinical Oncology (1983 to July 2006). Proceedings of international meetings (Bi-annual meetings of the American Society of Clinical Oncology, The European Society for Medical Oncology, The European Cancer Conference and The San Antonio Breast Cancer Symposium) were searched for any relevant trials. Reference lists of primary articles and reviews were also searched for additional trials (Pavlakis et al, 2005). Authors of the trials were contacted to identify any missing or unpublished trials.

\section{Critical evaluation of the selected trials}

The study types included in the systematic review were phase III clinical trials of oral clodronate therapy and survival in breast cancer patients. We identified and reviewed eligible articles independently to minimise the risk of selection bias and final decisions were reached by consensus. Trials that examined overall, bone metastasis-free or nonskeletal metastasis-free survival were included in our meta-analysis.

\section{Data abstraction}

The authors independently reviewed and abstracted the information and data using standardised data forms. Abstraction included information on pertinent methodological aspects of the study design, demographic characteristics of the participants and patient population recruited to the trial.

Whenever possible, the following information was extracted from the publications: (1) the number of patients involved in the treatment and control groups; (2) the hazard ratio (HR) with $95 \%$ confidence interval (CI) for 5-year overall, bone metastasis-free and nonskeletal metastasis-free survival. With observed death cases for both groups, HR with $95 \%$ CI were estimated using the method described by Parmar et al (1998) if a $P$-value from the comparison of two overall survival (Elomaa et al, 1988; Kristensen et al, 1999; Mardiak et al, 2000; Saarto et al, 2001) or other survival curves (Kanis et al, 1996; Kristensen et al, 1999) was provided or if event rates for treatment and control groups were available (Kanis et al, 1996) or could be derived by assuming exponential survival distribution (Paterson et al, 1993). Sometimes, Kaplan-Meier curves or survival tables were provided instead of $\mathrm{HR}$ and 95\% CI, in this case, HRs with 95\% CI were estimated from Kaplan-Meier curves using the method described by Parmar et al (1998) with the number of patients at risk at the beginning of the study (Kanis et al, 1996; Mardiak et al, 2000; Saarto et al, 2001) or the method described by Williamson et al (2002) with the number of patients at risk at some time points during the period of follow-up (Diel et al, 1998; Kristensen et al, 1999). If $\mathrm{HR}$ and 95\% CI can be estimated for less than or greater than 5-year survival (Elomaa et al, 1988; Paterson et al, 1993; Kanis et al, 1996; Kristensen et al, 1999; Mardiak et al, 2000; Powles et al, 2006) instead of exact 5 -year survival, constant HR was assumed and this HR together with its $95 \%$ CI were used as an estimate of the 5-year survival HR and $95 \%$ CI. If the estimated HR and 95\% CI derived were not consistent with the conclusions of the published paper, then the data for the particular paper were excluded (Paterson et al, 1993).

\section{Statistical analysis}

Funnel plots, together with Begg's rank correlation test and Egger's regression asymmetry test were used to assess publication bias (Sutton et al, 2000). In addition, the Duval and Tweedie nonparametric 'trim and fill' method of accounting for publication bias was performed to formalise the use of funnel plots and adjust the meta-analysis by incorporating the theoretical missing trials (Sutton et al, 2000).

$Q$-statistic was used to investigate the degree of heterogeneity between trials. A $P$-value of $<0.1$ was interpreted as evidence of heterogeneity among the combined trials than would be expected by chance alone. $I^{2}$-statistical test (Higgins and Thompson, 2002) was carried out to describe the proportion of total variation caused by heterogeneity because the $Q$-statistic has low power in common situations of few studies and excessive power to detect clinically unimportant heterogeneity when there are many studies (Hardy and Thompson, 1998). $I^{2}$ of less than $30 \%$ of the variability in point estimate was considered as mild heterogeneity, more than $50 \%$ was notable heterogeneity, whereas in between was considered as moderate heterogeneity. In our study, the $I^{2}$-statistic found notable heterogeneity; therefore pooled estimates were derived using a random effects model (DerSimonian-Laird method) to account for interstudy heterogeneity. Meta-analyses were performed in patients who received adjuvant clodronate treatment and in patients who received clodronate treatment for their advanced disease, compared with those who received no active treatment. All analyses were performed using STATA version 7 (Stata Corp., College Station, TX, USA).

\section{RESULTS}

Of the articles identified, 13 trials investigated overall survival, bone metastasis-free survival or nonskeletal metastasis-free survival. Among these, Elomaa et al $(1987,1988)$ reported the same results from the same patients and therefore only Elomaa et al (1988) was included. Powles et al (2002), Atula et al (2003) and Powles et al (2006) reported results from the same group of patients, only one (Powles et al (2006)) reported 5-year overall survival, 5-year bone metastasis-free survival and 5-year nonskeletal metastasis-free survival and was included in our metaanalysis. The study by Saarto et al (2004) was an extended 10-year follow-up of patients from the study by Saarto et al (2001), whereas Leppa et al (2005) investigated the influence of clodronate treatment on serum postoperative matrix metalloproteinase-2 associated with the clinical outcome of the same group of patients, thus only one study (Saarto et al, 2001) where HR and 95\% CI could be derived was included in our study. Therefore, eight trials were considered in our study (Table 1). However, only seven studies (Table 2) were included in our meta-analysis because the estimated HR and 95\% CI from the published data of one study (Paterson et al, 1993) was not consistent with the reported conclusion of the study and therefore this particular study was excluded from our meta-analysis. Among these, three studies investigated adjuvant clodronate treatment in patients diagnosed with early breast cancer (Diel et al, 1998; Saarto et al, 2001; Powles et al, 2006), whereas four studies investigated clodronate treatment in advanced breast cancer patients (Elomaa et al, 1988; Kanis et al, 1996; Kristensen et al, 1999; Mardiak et al, 2000).

\section{Overall survival}

Both Begg's rank correlation test $(P=0.37)$ and Egger's regression asymmetry test $(P=0.46)$ did not find any significant publication bias in our meta-analysis; however, funnel plots suggest otherwise.

\section{Early breast cancer}

The $Q$-statistic showed the presence of heterogeneity among different trials included in our meta-analysis $(P<0.001)$. $I^{2}$ statistics also found notable heterogeneity (Table 3 ). Compared with breast cancer patients without clodronate treatment, Diel et al (1998) and Powles et al (2006) reported a statistically significant increase in overall survival for patients receiving adjuvant clodronate treatment (Table 2), whereas Saarto et al (2001) found the opposite trend (Table 2). The pooled result demonstrated no statistically significant difference in the overall survival between 
Table 3 Meta-analysis of overall survival, bone metastasis-free survival and nonskeletal metastasis-free survival

\begin{tabular}{|c|c|c|c|c|c|}
\hline Meta-analysis & \multicolumn{2}{|c|}{ No. of subjects } & Heterogeneity ( $P$-value) & $I^{2}(\%)$ & HR $(95 \% \mathrm{Cl})$ \\
\hline Advanced breast cancer only & 456 & 458 & $<0.001$ & 82 & $0.71(0.40,1.26)$ \\
\hline Adjuvant clodronate treatment & 827 & 826 & $<0.001$ & 91 & $0.75(0.31,1.82)$ \\
\hline \multicolumn{6}{|l|}{ Bone metastasis-free survival } \\
\hline \multicolumn{6}{|l|}{ Nonskeletal metastasis-free sunvival } \\
\hline Advanced breast cancer only & 321 & 326 & $<0.001$ & 88 & $0.95(0.31,2.9 \mid)$ \\
\hline Adjuvant clodronate treatment & 827 & 826 & $<0.001$ & 89 & $0.89(0.40,1.98)$ \\
\hline
\end{tabular}

$\mathrm{Cl}=$ confidence interval; $\mathrm{HR}=$ hazard ratio.

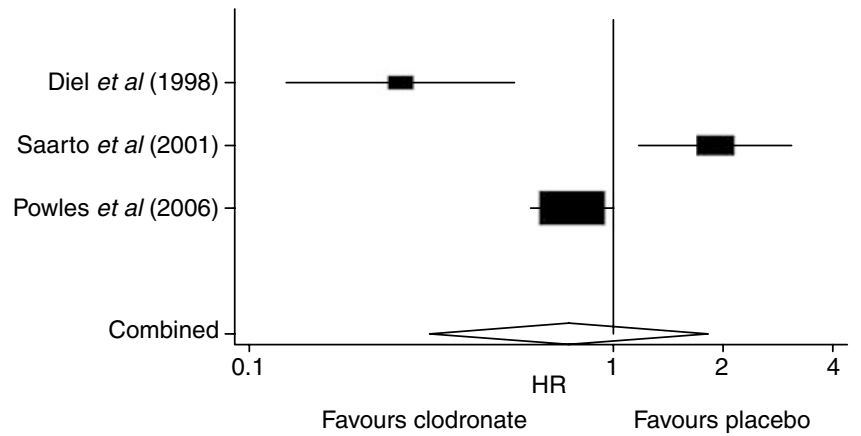

Figure I Forest plot of overall survival in early breast cancer patients receiving adjuvant clodronate therapy.

patients treated with adjuvant clodronate therapy and those receiving no treatment $(\mathrm{HR}=0.75,95 \% \mathrm{CI}=0.31,1.82)$ (Figure 1$)$.

\section{Advanced breast cancer}

Both $Q$-statistic and $I^{2}$-statistic demonstrated the presence of notable heterogeneity among the trials when only advanced breast cancer patients were included (Table 2). Meta-analysis showed that clodronate did not change the overall survival among patients with advanced breast cancer $(\mathrm{HR}=0.73,96 \% \mathrm{CI}=0.46,1.14)$.

\section{Bone metastasis-free survival}

Five trials investigated bone metastasis-free survival among breast cancer patients receiving clodronate treatment or no active treatment (Kanis et al, 1996; Diel et al, 1998; Mardiak et al, 2000; Saarto et al, 2001; Powles et al, 2006). Begg's rank correlation test $(P=1.00)$, Egger's regression asymmetry test $(P=0.77)$ and funnel plots did not find any significant publication bias in our meta-analysis.

\section{Early breast cancer}

When analysis was restricted to those receiving adjuvant clodronate treatment, both $Q$-statistic and $I^{2}$ statistic detected the presence of notable heterogeneity among the trials (Table 2). Pooled analysis did not find any statistically significant difference in the time to appearance of bone metastasis in patients who received adjuvant clodronate treatment compared with those who did not $(\mathrm{HR}=0.68,95 \% \mathrm{CI}=0.38,1.23)$ (Figure 2).

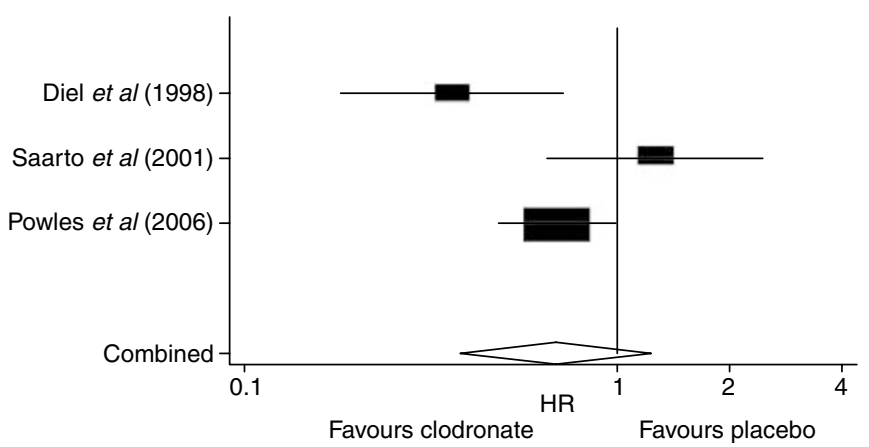

Figure 2 Forest plot of bone metastasis-free survival in early breast cancer patients receiving adjuvant clodronate therapy.

\section{Advanced breast cancer}

Our meta-analysis suggested no difference in the appearance of bone metastasis between advanced breast cancer patients who received clodronate therapy and those who did not $(\mathrm{HR}=0.68$, $95 \% \mathrm{CI}=0.23,1.98)$.

\section{Nonskeletal metastasis-free survival}

Four trials provided information on nonskeletal metastasis-free survival (Diel et al, 1998; Mardiak et al, 2000; Saarto et al, 2001; Powles et al, 2006). Among these four trials, Diel et al (1998) reported that adjuvant clodronate treatment delayed the occurrence of nonskeletal metastasis, whereas Saarto et al (2001) found the opposite trend. Begg's rank correlation test $(P=1.00)$, Egger's regression asymmetry test $(P=0.99)$ and funnel plots did not establish any significant publication bias.

\section{Early breast cancer}

Our meta-analysis demonstrated no statistically significant delay in the occurrence of nonskeletal metastases between patients receiving adjuvant clodronate therapy and those receiving no treatment $(\mathrm{HR}=0.89,95 \% \mathrm{CI}=0.40,1.98)$ (Figure 3$)$.

\section{DISCUSSION}

Our meta-analysis examined the effects of clodronate on 5-year overall, bone metastasis-free and nonskeletal metastasis-free survival among early breast cancer patients receiving adjuvant clodronate treatment and advanced breast cancer patients. There was no evidence to suggest that clodronate therapy improves 


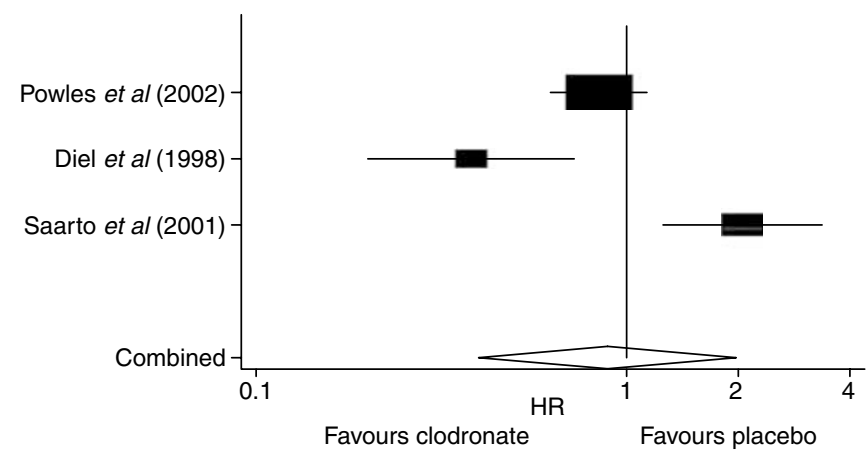

Figure 3 Forest plot of nonskeletal metastasis-free survival in early breast cancer patients receiving adjuvant clodronate therapy.

overall, nonskeletal metastasis-free survival or bone metastasisfree survival significantly in either group of patients. However, larger trials may be worthwhile conducting to assess the true effect of clodronate, as currently there are a limited number of trials and patients.

Potential limitations exist because of the availability, quality and heterogeneity of the published data. In our analyses, we assumed constant $\mathrm{HR}$ and used this together with its $95 \% \mathrm{CI}$ if an estimate for 5-year survival could not be derived from the available data, as was the case for overall survival (Elomaa et al, 1988; Kanis et al, 1996; Diel et al, 1998; Mardiak et al, 2000; Powles et al, 2006). Imposing more stringent criteria by including only 5-year survival would not alter the trend of the effect of clodronate on survival among either early or advanced breast cancer patients. Furthermore, all individual trials included in our study compared clodronate therapy with an equivalent placebo except one (Diel et al, 1998). Sensitivity analysis by excluding this trial among adjuvant studies did not lead to a different conclusion. This suggests that the trial design with placebo or without placebo may not affect the results in terms of survival.

Patients received surgery, radiotherapy and adjuvant systemic therapy according to local protocols. No assessment of any treatment with tamoxifen or aromatase inhibitor therapy was conducted among two trials (Elomaa et al, 1988; Kanis et al, 1996) when such therapies are known to prolong survival in hormonepositive breast cancer patients (Goss et al, 2005; Thurlimann et al, 2005; Kaufmann and Rody, 2006; Wardley, 2006). Although traditional prognostic factors were well balanced (such as age, menopausal status and tumour size), other confounding factors such as progesterone receptor status were not balanced (Saarto et al, 2001) and the oestrogen receptor status is unknown in the patient population of three trials (Elomaa et al, 1988; Kanis et al, 1996; Mardiak et al, 2000). Such factors would contribute to the heterogeneity of our study to some extent. Therefore, the randomeffects model only was adopted in our analysis to consider the heterogeneity by providing a wider CI.

Publication bias is a well-known limitation of meta-analyses. To adjust for publication bias, the Duval and Tweedie nonparametric 'trim and fill' method was adopted. Meta-analysis with or without the 'trim and fill' method did not result in different conclusions, indicating that our results are statistically robust.

In conclusion, the use of oral clodronate in breast cancer patients does not significantly increase 5-year overall, nonskeletal metastasis-free or bone metastasis-free survival in early breast cancer patients receiving adjuvant clodronate treatment or patients receiving clodronate for their advanced breast cancer.

\section{ACKNOWLEDGEMENTS}

We thank Dr Nan Soon Wong for editorial advice. This work has not been published in any other journal or publications. This work has been presented as a poster at the European Institute of Oncology's 8th Milan Breast Cancer Conference, June 21 -23, 2006.

\section{REFERENCES}

Atula S, Powles T, Paterson A, McCloskey E, Nevalainen J, Kanis J (2003) Extended safety profile of oral clodronate after long-term use in primary breast cancer patients. Drug Safety 26: 661-671

Coleman RE (1997) Skeletal complications of malignancy. Cancer 80: $1588-1594$

Dando TM, Wiseman LR (2004) Clodronate : a review of its use in the prevention of bone metastases and the management of skeletal complications associated with bone metastases in patients with breast cancer. Drugs Aging 21: 949-962

Diel IJ, Solomayer EF, Costa SD, Gollan C, Goerner R, Wallwiener D, Kaufmann M, Bastert G (1998) Reduction in new metastases in breast cancer with adjuvant clodronate treatment. $N$ Engl J Med 339: $357-363$

Elomaa I, Blomqvist C, Porkka L, Holmstrom T, Taube T, Lamberg-Allardt C, Borgstrom GH (1988) Clodronate for osteolytic metastases due to breast cancer. Biomed Pharmacother 42: 111-116

Elomaa I, Blomqvist C, Porkka L, Lamberg-Allardt C, Borgstrom GH (1987) Treatment of skeletal disease in breast cancer: a controlled clodronate trial. Bone 8(Suppl 1): S53-S56

Goss PE, Ingle JN, Martino S, Robert NJ, Muss HB, Piccart MJ, Castiglione $\mathrm{M}, \mathrm{Tu} \mathrm{D}$, Shepherd LE, Pritchard KI, Livingston RB, Davidson NE Norton L, Perez EA, Abrams JS, Cameron DA, Palmer MJ, Pater JL (2005) Randomized trial of letrozole following tamoxifen as extended adjuvant therapy in receptor-positive breast cancer: updated findings from NCIC CTG MA.17. J Natl Cancer Inst 97: 1262 - 1271

Hardy RJ, Thompson SG (1998) Detecting and describing heterogeneity in meta-analysis. Stat Med 17: $841-856$

Higgins JPT, Thompson SG (2002) Quantifying heterogeneity in a metaanalysis. Stat Med 21: 1539-1558
Kanis JA, Powles T, Paterson AH, McCloskey EV, Ashley S (1996) Clodronate decreases the frequency of skeletal metastases in women with breast cancer. Bone 19: 663-667

Kaufmann M, Rody A (2006) Extended breast cancer treatment with an aromatase inhibitor (Letrozole) after tamoxifen: why, who and how long? Eur J Obstet Gynecol Reprod Biol 126: 146-154

Kristensen B, Ejlertsen B, Groenvold M, Hein S, Loft H, Mouridsen HT (1999) Oral clodronate in breast cancer patients with bone metastases: a randomized study. J Intern Med 246: 67-74

Leppa S, Saarto T, Vehmanen L, Blomqvist C, Elomaa I (2005) Clodronate treatment influences MMP-2 associated outcome in node positive breast cancer. Breast Cancer Res Treat 90: 117-125

Lipton A (2003) Bisphosphonates and metastatic breast carcinoma. Cancer 97: $848-853$

Mardiak J, Bohunicky L, Chovanec J, Salek T, Koza I (2000) Adjuvant clodronate therapy in patients with locally advanced breast cancer long-term results of a double-blind randomized trial. Slovak Clodronate Collaborative Group. Neoplasma 47: 177-180

Parmar MK, Torri V, Stewart L (1998) Extracting summary statistics to perform meta-analyses of the published literature for survival endpoints. Stat Med 17: 2815-2834

Paterson AH, Powles TJ, Kanis JA, McCloskey E, Hanson J, Ashley S (1993) Double-blind controlled trial of oral clodronate in patients with bone metastases from breast cancer. J Clin Oncol 11: 59-65

Pavlakis N, Schmidt RL, Stockler M (2005) Bisphosphonates for breast cancer. [Systematic Review] Cochrane Breast Cancer Group Cochrane Database of Systematic Reviews 4, 2006

Powles T, Paterson A, McCloskey E, Schein P, Scheffler B, Tidy A, Ashley S, Smith I, Ottestad L, Kanis J (2006) Reduction in bone relapse and 
improved survival with oral clodronate for adjuvant treatment of operable breast cancer [ISRCTN83688026]. Breast Cancer Res 8: R13

Powles T, Paterson S, Kanis JA, McCloskey E, Ashley S, Tidy A, Rosenqvist K, Smith I, Ottestad L, Legault S, Pajunen M, Nevantaus A, Mannisto E, Suovuori A, Atula S, Nevalainen J, Pylkkanen L (2002) Randomized, placebo-controlled trial of clodronate in patients with primary operable breast cancer. J Clin Oncol 20: 3219-3224

Saarto T, Blomqvist C, Virkkunen P, Elomaa I (2001) Adjuvant clodronate treatment does not reduce the frequency of skeletal metastases in nodepositive breast cancer patients: 5-year results of a randomized controlled trial. J Clin Oncol 19: $10-17$

Saarto T, Vehmanen L, Virkkunen P, Blomqvist C (2004) Ten-year followup of a randomized controlled trial of adjuvant clodronate treatment in node-positive breast cancer patients [see comment]. Acta Oncol 43: $650-656$
Sutton AJ, Abrams KR, Jones DR, Sheldon TA, Song F (2000) Part A: MetaAnalysis Methodology: the Basics. Methods for Meta-Analysis in Medical Research. John Wiley \& Sons Ltd: Chichester

Thurlimann B, Keshaviah A, Coates AS, Mouridsen H, Mauriac L, Forbes JF, Paridaens R, Castiglione-Gertsch M, Gelber RD, Rabaglio M, Smith I, Wardly A, Price KN, Goldhirsch A, Breast International Group 1-98 Collaborative, G (2005) A comparison of letrozole and tamoxifen in postmenopausal women with early breast cancer. $N$ Engl J Med 353: $2747-2757$

Wardley AM (2006) Emerging data on optimal adjuvant endocrine therapy: Breast International Group trial 1-98/MA.17. Clin Breast Cancer 6(Suppl 2): $S 45-S 50$

Williamson PR, Smith CT, Hutton JL, Marson AG (2002) Aggregate data meta-analysis with time-to-event outcomes. Stat Med 21: $3337-3351$ 